\title{
Development of Molecular Tools to Differentiate Sri Lankan Wild Boar (Sus scrofa affinis) Meat from Exotic and Village Pig (Sus scrofa domestica) Meat
}

\author{
M. Samaraweera*, S.M.C. Himali ${ }^{1}$, S.C. Zeng ${ }^{2}$ \\ H. Jianlin ${ }^{2}$ and P. Silva ${ }^{1}$ \\ Postgraduate Institute of Agriculture \\ University of Peradeniya \\ Sri Lanka
}

\begin{abstract}
Reliable labelling of meat products is important in the food industry in order to ensure food safety, prevent fraud adulterations and avoid conflict with socio-religious practices. In Sri Lanka, wild boar meat is known to be substituted with pork to meet the demand. There are many court cases on illegal selling and transportation of wild boar meat. Thus, reliable methods to identify wild boar meat are necessitated. Therefore, the objective of the present study was to differentiate meat of wild boar from exotic and domestic swine using mitochondrial DNA markers. The entire mitochondrial DNA D-loop region was amplified using the forward primer, 5'CCAAGACTCAAGGAAGGAGA3' and reverse primer, 5'GGCGCGGATACTTGCATGTG3'. From the sequence analysis several repetitive sequences of 5'CGTGCGTACA (10 bp) was observed indicating sequence heteroplasmy in porcine mitochondrial DNA D-loop region. Avoiding these repetitive sequences D-loop exhibited 17 polymorphic sites which enable differentiation of Sri Lankan wild boar from exotic and village pigs. Furthermore, a unique repeat of AAACCACAC (9 bp) was observed within the Sri Lankan wild boar samples analyzed. Targeting two polymorphic sites PCRRFLP analysis was performed, using forward primer 5'GTGCTACGAAAGCAGG3' and same reverse primer followed by a simple restriction digestion using cost effective Dra 1 enzyme. Upon restriction digestion, wild boar produced two bands of $150 \mathrm{bp}$ and $60 \mathrm{bp}$ differing them from exotic and village pigs. This technique can be routinely applied to verify wild boar meat.
\end{abstract}

Keywords: Meat identification, mitochondrial DNA D-loop region, PCR-RFLP, wild boar

\section{INTRODUCTION}

The increasing world population and the increasing demand for meat and meat products lower the per capita availability of protein of animal origin, resulting fraudulent substitution or adulteration of costly or highly demanded meat with cheaper ones (Koh et al., 1998). Awareness on fraud substitutions or adulterations is necessary in the food industry, considering the food habits of the individuals. For example, some may have food allergies to certain meat species: Jews and Muslims consume only specified food types approved by their religion such as 'Kosher' and 'Halal' respectively. Hindus do not consume beef due to

\footnotetext{
${ }^{1}$ Department of Animal Science, Faculty of Agriculture, University of Peradeniya,Peradeniya, Sri Lanka

${ }^{2}$ Institute of Animal Science, Chinese Academy of Agricultural Sciences (CAAS), Beijing, China Author for correspondence: amamalsh@gmail.com
} 
religious dietary restrictions and vegetarians totally restrict the consumption of meat. Thus, the knowledge on exact source or origin of animal protein is crucial in food safety where the consumers demand the traceability of meat from farm to fork.

Despite the high price, game meat is highly popular and highly demanded in meat industry, where substitutions and adulterations are commonly seen. Game meat is favored by many people due to diverse reasons such as intense flavor, specific texture, low fat and cholesterol content, lack of anabolic steroids and other drugs and increased awareness on organic products (La Neve et al., 2008; Hoffman \& Wiklund, 2006).

Though, game animal hunting is popular in many countries, hunting of wild animals is restricted by law in Sri Lanka. Among the game meats in the country, wild boar meat is highly popular. Although, the conservation status of wild boar is not classified as threatened or near threatened, hunting of wild boar is restricted in the country. The Fauna and Flora Ordinance in Sri Lanka states; "no animal shall be hunted, killed or taken and no plant shall be damaged, collected, or destroyed, in a strict natural reserve, national park, nature reserve or jungle corridor" (3,44 of 1964). The ordinance also bans the sale or transport of wild boar meat, even that of wild boars killed under the exemption for animals that damage crops. There are abundant court cases due to illegal selling and keeping of wild boar meat. When wild animals are hunted, phenotype markers are often destroyed or intentionally removed to conceal the species of origin, misleading the relevant authorities of wild life conservation (Rastogi et al., 2007). Therefore, identification of wild boar meat is important in making correct and fair decision in keeping with the country's law and order.

On the other hand, wild animals are valuable genetic resources which can be effectively utilized for sustainable food supply in the future. Therefore, to safeguard the wild animals as well as to avoid economic fraudulence, it is required to have reliable and sensitive methods of meat identification (Dooley et al., 2004). Sensory analysis, anatomical differences, histological differentiation of the hair that may exist on the meat, properties of tissue fat, level of glycogen in muscle tissue and protein based techniques (electrophoretic, chromatographic, immunological assays) are some of the methods used for meat identification (Ashoor et al., 1998; Arslan et al., 2005). But due to problems of specificity, some of these methods are inadequate for routine analysis (Arslan et al., 2005).

DNA-based techniques are now widely used to identify the species of origin of meat due to its ubiquitous nature (Wolf et al., 1999). DNA is a stable molecule under high temperature, high pressure and chemical treatments used in processing (Arslan et al., 2006). DNA-based methods for meat identification include Polymerase Chain Reaction-Restriction Fragment Length Polymorphism (PCR-RFLP) (Fajardo et al., 2006), Random Amplified Polymorphic DNA (RAPD), DNA hybridization and Single Strand Conformational Polymorphism (SSCP) (Dooley et al., 2004).

Both nuclear and mitochondrial DNA (mtDNA) have been used for these studies. In the case of mtDNA, cytochrome $b$ gene (Hwang et al., 2004), 12S (Fajardo et al., 2008), 16S (Rastogi et al., 2007), 18S (Meyer et al., 1995) ribosomal RNA (rRNA) subunits and displacement loop region (D-loop) (Fajardo et al., 2007) have been used for species identification. Due to maternal inheritance of mtDNA no recombination mechanism exists as in the nuclear DNA to eliminate error once a mutation occurred (Hwang et al., 2004). Thus, accumulation of these point mutations allows discrimination of closely related species (Wolf 
et al., 1999). However, attempts on within species identification using these methods are scanty.

Therefore, identification of meat within species, at least at subspecies or breed levels need to be further investigated. Thus, objective of the present study is to identify the meat of wild boar from exotic swine breeds and village type using mtDNA based techniques.

\section{MATERIALS AND METHODS}

The experiments were carried out at the Agriculture Biotechnology Centre, Faculty of Agriculture, University of Peradeniya, Sri Lanka and CAAS-ILRI Joint Laboratory on Livestock and Forage Genetic Resources (JLLFGR), Institute of Animal Science, Chinese Academy of Agricultural Sciences (CAAS), Beijing, China.

\section{Sample collection and storage}

Meat or blood samples of wild boar (Sus scrofa affinis) were obtained from Uda Peradeniya Livestock Experimental Field Station, University of Peradeniya and from Gampola, Galaha, Kadugannawa and Kegalle areas. Local domestic pig samples were collected from Negumbo and Beruwala coastal areas along the western side of the island where the local pigs were reared extensively. The commercial pig samples of 'Large white', 'Land race' and 'Duroc' breeds were collected from a commercial private farm (Chutiduwa farm, Katuneriya, Negumbo) and from Uda Peradeniya Livestock Experimental Field Station, University of Peradeniya. Meat and blood samples were stored at $-20^{\circ} \mathrm{C}$ and $4{ }^{\circ} \mathrm{C}$ respectively until they were used for the analysis.

\section{DNA extraction}

Genomic DNA was obtained from meat using the salting-out protocol as described by Jianlin (2004).

\section{DNA quantification}

DNA quantification was carried out using NanoDrop spectrophotometer ND1000 (Thermo Fisher Scientific, Wilmington, DE, USA). The measurement (ng/ $\mu \mathrm{l})$ was obtained using the PC based software.

\section{DNA amplification}

PCR amplification of mtDNA was done at three different as follows.

\section{Amplification of a fragment of mtDNA D-loop region}

A fragment of the mtDNA D-loop region was amplified as described by Montiel-sosa et al. (2000). The following primer pair was used for the amplification.
pig F 5' AACCCTATGTACGTCGTGCAT (15592)
pig R 5' ACCATTGACTGAATAGCACCT (16124)
primer $1 \mathrm{~F}$
primer $1 \mathrm{R}$

Amplification of DNA was carried out in a final volume of $50 \mu 1$ in tubes containing total DNA (20 ng/ $\mu$ l), $10 \times$ reaction buffer, $10 \mathrm{mM}$ of each dATP, dCTP, dGTP, dTTP (Promega, Madison, WI , USA), $20 \mathrm{pmol} / \mu \mathrm{l}$ of each primer (Genetech, Sri Lanka) and $5 \mathrm{U}$ of Taq DNA polymerase (Promega, Madison, WI, USA). After $5 \mathrm{~min}$ of initial denaturation at $94{ }^{\circ} \mathrm{C}, 30$ 
cycles of amplification at $94{ }^{\circ} \mathrm{C}$ for $45 \mathrm{sec}$ (denaturation), $62{ }^{\circ} \mathrm{C}$ for $45 \mathrm{sec}$ (annealing), and $72{ }^{\circ} \mathrm{C}$ for $1 \mathrm{~min}$ (elongation) were carried out in a thermal cycer (Applied biosystems, Foster city, California). Amplified products were electrophoresed in a $2 \%$ agarose gel in TBE buffer, observed by staining with ethidium bromide under UV transillumination (BINTA 2020D).

\section{Amplification of the entire mtDNA D-loop region}

Complete D-loop mtDNA was amplified using the primer pair given below.

$$
\begin{array}{ll}
\text { L-strand (forward) (5'CCAAGACTCAAGGAAGGAGA3') } & \text { primer 2F } \\
\text { H-strand (reverse) (5'GGCGCGGATACTTGCATGTG3') } & \text { primer 2R }
\end{array}
$$

PCR amplification was performed in a gene Amp PCR systems 9700 (Applied biosystems, Foster city, CA, USA). The PCR reaction was performed in a total volume of $50 \mu$, containing $50 \mathrm{ng} / \mu \mathrm{l}$ of genomic DNA, $10 \mathrm{ng} / \mu \mathrm{l}$ of both forward and reverse primers, $2.5 \mathrm{mM}$ of dNTP, $10 \mathrm{x}$ reaction buffer, $5 \mathrm{U}$ taq polymerase (Tiangen, Beijing, China). The 30 cycles of amplification was carried out with $94{ }^{\circ} \mathrm{C} 30 \mathrm{sec}$ (denaturation), $60{ }^{\circ} \mathrm{C} 45 \mathrm{sec}$ (annealing), and $72{ }^{\circ} \mathrm{C} 90 \mathrm{sec}$ (elongation). The cycles were initiated by initial denaturation at $94{ }^{\circ} \mathrm{C}$ for 5 min and terminated by final extension at $72{ }^{\circ} \mathrm{C}$ for $10 \mathrm{~min}$. Amplified products were electrophoresed in a $2 \%$ agarose gel in TBE buffer, observed by staining with ethidium bromide under UV transillumination (BINTA 2020D).

The amplified products were sequenced (Beijing Sunbiotech, China) and the sequences obtained were aligned using the Chromas software package version 2.0 and Mega software packages version 5.0.

\section{PCR-RFLP analysis of mitochondrial D-loop region}

Restriction maps were developed for wild boar, local and domestic pigs. The sequences were analyzed by Cleaver and Primer premier 5 software packages. After detailed comparison a cost effective enzyme Dra I was selected.

The following new forward primer (3F) was designed to amplify only the target polymorphic site of mtDNA D-loop region along with the $2 \mathrm{R}$ reverse primer.

5'GTGCTACGAAAGCAGG3'

primer $3 \mathrm{~F}$

\section{RESULTS AND DISCUSSION}

Mitochondrial DNAs are used extensively for meat identification studies due to its higher evolution rate and sequence diversity compared to nuclear DNA (Wolf et al., 1999). On the other hand, mtDNA is maternally inherited and only one allele exists in an individual. Therefore, accumulated point mutations can be easily detected in the sequence analysis due to absence of recombination mechanisms facilitating discrimination of closely related species (Hwang et al., 2004). Furthermore, only a small amount of the sample will be adequate for mtDNA analysis due to presence of a large number of mitochondria in each cell (Montielsosa et al., 2000). The D-loop is included in the control region of the mtDNA and is flanked by the tRA ${ }^{\text {pro }}$ and tRA $^{\text {phe }}$ mt genes (Sbisa et al., 1997). MtDNA D-loop region has the highest 
substitution rate and is the most rapidly evolving region of the mitochondrial genome. Thus, mtDNA D-loop region was targeted in this study for identification of wild boar meat from exotic and village pigs.

\section{Polymorphisms in the mitochondrial DNA D-loop region}

Amplifiaction of DNA by the primers $1 \mathrm{~F}$ and $1 \mathrm{R}$ resulted in amplicons of $\sim 500 \mathrm{bp}$ (data not shown). Single nucleotide point mutations generated from these partial D-loop sequences were not adequate to differentiate wild boar from other pigs. However, Montiel-sosa et al. (2000) distinguished wild boar from pork using a restriction site derived from one base deletion in wild boar with respect to pig mitochondrial DNA. But this deletion was not observed in this study. Therefore, amplification of entire D-loop was carried out to explore single nucleotide point mutations.

The primer pair $2 \mathrm{~F}$ and $2 \mathrm{R}$ described above amplified a region of $\sim 1200 \mathrm{bp}$ from swine but failed to produce any detectable amplicons from chicken, sheep and yak (Fig. 1). Thus, the primer pair used is sensitive enough to specifically amplify the swine D-loop region.

The amplified nucleotide sequence of swine includes several repetitive sequences of 5'CGTGCGTACA (10 bp) in the D-loop indicating sequence heteroplasmy. Though, Sus scrofa mitochondrial genome is about $16 \mathrm{~kb}$, the length is not specific due to presence of these tandem repeats (5' CGTGCGTACA) in the D-loop (Lin et al., 1999). According to Ghivizzani et al. (1993) this 10 bp sequence is repeated tandemly 14-29 times in different porcine mitochondrial genomes. The intracellular variability may be due to the repeated and self complementary properties of this sequence which would favour mispairing and lead to replication slippage.

Thus, forward and reverse compliments of 17 wild boars, 20 village pigs and 27 exotic pig samples collected from Sri Lanka were aligned separately as forward complement and reverse complement avoiding the tandem repeats to find out intra-species nucleotide polymorphisms.

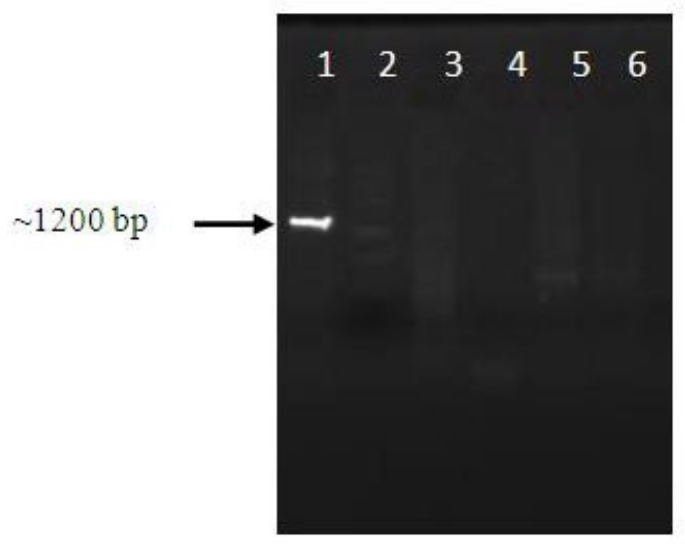

Fig. 1. Electrophoretic analysis of the PCR products amplified from wild boar (lane 1), chicken (lane 3), sheep 1 (lane 4), shep 2 (lane 5), yak (lane 6). Molecular weight marker III, $200-4500$ bp (lane 2)

The aligned sequences were compared with sequence data from Larson et al. (2010) (from 16 countries representing Asia and Pacific) and sequences downloaded from National Centre 
for Biotechnology Information (NCBI) data base to find a polymorphic DNA region. After detailed comparison, 8 and 9 polymorphic sites in wild boar were identified from forward and reverse complements (Table 1), respectively. Apart from these polymorphisms, a repeat of AAA CCA CAC (Fig. 2) (9 bp) was observed within the reverse complement in all the wild boars except WB 7, 8 and other downloaded sequences. Despite the two negative wild boar samples it was confirmed that this insertion is unique to Sri Lankan wild boar.

Table 1. Summary of polymorphic sites which can be used to differentiate Sri Lankan wild boar from village pigs and exotic pigs (Duroc, Land race and Large white)

\begin{tabular}{|c|c|c|c|c|c|}
\hline & $\begin{array}{l}\text { Polymorphic } \\
\text { site no. }\end{array}$ & Position $^{a}$ & $\begin{array}{c}\text { Sri Lankan wild } \\
\text { boar } \\
(\text { WB } 1-6 \& 9-17)^{b} \\
\end{array}$ & $\begin{array}{c}\text { Sri Lankan wild } \\
\text { boar } \\
\text { (WB } 7 \& 8) \\
\end{array}$ & Others* \\
\hline \multirow{8}{*}{ 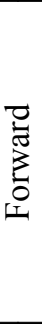 } & 1 & 15,452 & $\mathrm{C}$ & $\mathrm{T}$ & $\mathrm{T}$ \\
\hline & 2 & 15,523 & $\mathrm{C}$ & $\mathrm{G}$ & $\mathrm{G}$ \\
\hline & 3 & 15,562 & $\mathrm{~T}$ & $\mathrm{C}$ & $\mathrm{C}$ \\
\hline & 4 & 15,756 & G & A & A \\
\hline & 5 & 15,841 & A & $\mathrm{T}$ & $\mathrm{T}$ \\
\hline & 6 & 16,097 & $\mathrm{~T}$ & $\mathrm{C}$ & $\mathrm{C}$ \\
\hline & 7 & 16,103 & G & A & A \\
\hline & 8 & 16,108 & $\mathrm{~T}$ & $\mathrm{C}$ & $\mathrm{C}$ \\
\hline \multirow{9}{*}{ 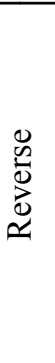 } & 1 & 16,674 & G & A & A \\
\hline & 2 & 16,682 & $\mathrm{C}$ & $\mathrm{T}$ & $\mathrm{T}$ \\
\hline & 3 & 16,690 & $\mathrm{~T}$ & $\mathrm{C}$ & $\mathrm{C}$ \\
\hline & 4 & 16,703 & $\mathrm{~T}$ & A & A \\
\hline & 5 & 16,742 & $\mathrm{C}$ & $\mathrm{T}$ & $\mathrm{T}$ \\
\hline & 6 & 16,774 & $\mathrm{~T}$ & $\mathrm{C}$ & $\mathrm{C}$ \\
\hline & 7 & 16,887 & $\mathrm{~T}$ & C & C \\
\hline & 8 & 16,925 & $\mathrm{~T}$ & $\mathrm{C}$ & $\mathrm{C}$ \\
\hline & 9 & 16,927 & A & $\mathrm{G}$ & $\mathrm{G}$ \\
\hline
\end{tabular}

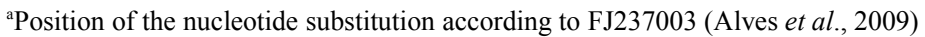

${ }^{\mathrm{b}}$ Gene bank accession numbers of wild boar samples (reverse only): WB 1-6: JN858911-JN858916; WB 9-

17:JN858917-JN858925.

*Village pig (VP1-20), Duroc (D1-12), Land race (LR1-8), Large white (LW1-7)

Interestingly, the two wild boar samples (WB $7 \&$ WB 8) used in the study were different from all other wild boars. The preliminary mtDNA analysis revealed that those two samples were homologous to village and exotic pig sequences. The most probable reason for this sequence diversity is crossing of wild boars to exotic sows. Though, wild boar meat is favored by many due to its intense flavor compared to exotic pig meat, wild boar meat is less available in the island due to reasons such as laws enforced. Thus, crossing of exotic sows to wild boar and selling of meat from crossbred offspring as wild boar meat is a common practice in the country (Chandrasiri, 2004). Therefore, to facilitate mating with wild boar the exotic sows were known to be tied up in the jungles (Subalini et al., 2010).

Though, the village pigs were assumed to have evolved as a result of gradual domestication of wild pigs of Sri Lanka (Rajamahendran et al., 1986), the village pig sequences obtained in this study suggests that they resemble more of exotic breeds rather than wild pigs. According to Chandrasiri (2004) there were recent introgression of exotic genome due to the state sponsored programs conducted to upgrade the local population with imported semen or live 
animals of Large white, Land race and Duroc breeds. In most of these upgrading programs paternal and not maternal introgression is possible as it is the imported semen or boar that is used commonly in the breeding program. Since mt DNA is always maternally originated, according to the present findings the origin of domestic local pig becomes questionable.

However, the polymorphism observed in D-loop sequence can be used to differentiate Sri Lankan wild boar from village and exotic pigs from Sri Lanka and from other Asian Pigs even though they are closely related.

\section{Restriction fragment length polymorphism (RFLP) analysis of D-loop region}

PCR-RFLP is one of the main genetic tools adopted by researchers to distinguish meat species. Thus, PCR-RFLP technique was a tool of choice in this study in order to differentiate meat of wild boar from others owing to the advantages such as simplicity, low cost, speed and better resolving power compared to DNA sequencing and sequence analysis (Fajardo et al., 2006).

In order to facilitate better detection of restriction fragments, a new forward primer $(3 \mathrm{~F})$ along with the reverse primer, $2 \mathrm{R}$ was used to amplify a DNA fragment ( $\sim 270 \mathrm{bp})$ targeting the restriction site which was derived using the $8^{\text {th }}$ and $9^{\text {th }}$ polymorphic sites of the reverse complement (Table 1 \& Fig. 2). The cleavage pattern obtained after digestion with Dra I restriction enzyme is given in Fig. 3. The amplified DNA fragment of wild boar produced two bands of $150 \mathrm{bp}$ and $60 \mathrm{bp}$ upon restriction digestion where as exotic and village pig samples produced two bands of $210 \mathrm{bp}$ and $60 \mathrm{bp}$. Thus, use of the PCR-RFLP technique targeting the mtDNA D-loop region is a promising method to distinguish wild boar from exotic and domestic swine meats.

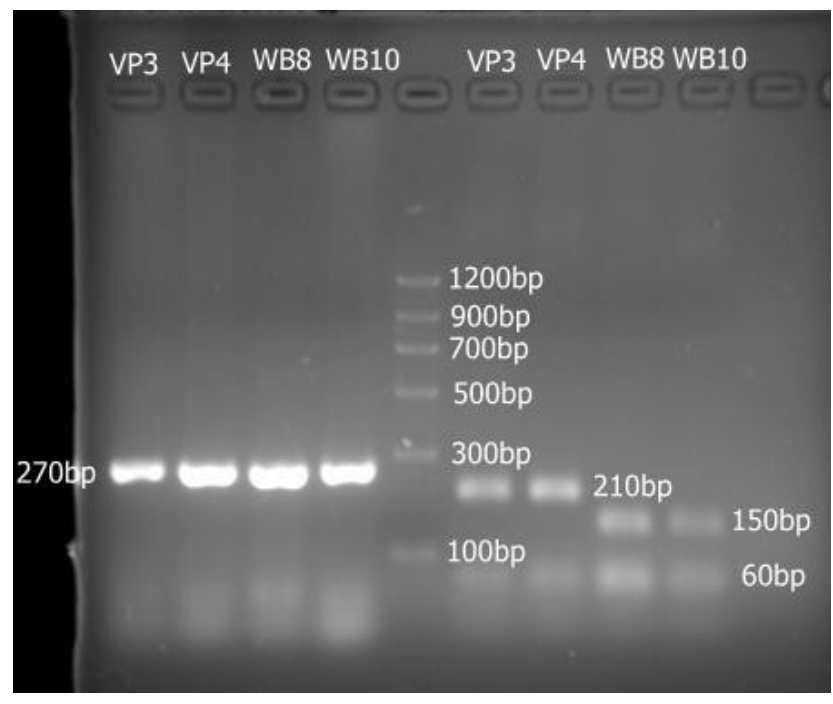

Fig. 3. PCR-RFLP patterns obtained after digestion of mt DNA amplicons with Dra $I$ restriction enzyme (right) and undigested DNA of $\sim 270$ bp (left). Samples are, village pig (VP), wild boar (WB) \& molecular weight marker (M)

However, chance of an intra-species mutation occurring at a restriction site and difficulties in detecting the crossbred individuals due to their maternal inheritance limits the use of mtDNA 
in meat authentication. Hence, mtDNA data should be used together with alternative nuclear markers such as Melanocortin Receptor 1 gene (MC1R) (Fajardo et al., 2008), actin-intron region (Rastogi et al., 2007) and glucosephosphate isomerase-processed pseudogene (GPIP) (Naya et al., 2003). The second phase of this study deals with use of nuclear markers for meat identification. 


\begin{tabular}{|c|c|c|c|c|c|c|c|c|c|c|c|c|c|c|c|c|c|c|c|c|c|c|c|c|c|c|}
\hline & & 5,757 & & 16, & 766 & & & & & & & & & & & & & & & & & & & & 16,767 & 6,7 \\
\hline eference & J237003) & TA ACA & $\mathrm{ACA}$ & C-- & --- & --- & --- & --- & --- & --- & --- & --- & --- & --- & --- & --- & --- & --- & --- & --- & --- & --- & --- & --- & & $\mathrm{ACC}$ \\
\hline id & IB1) & $\ldots \ldots$ & $\ldots$ &. $\mathrm{AA}$ & $\mathrm{ACC}$ & $\mathrm{ACA}$ & CAA & $\mathrm{ACC}$ & $\mathrm{ACA}$ & CAA & $\mathrm{ACC}$ & $\mathrm{ACA}$ & $\mathrm{CAA}$ & $\mathrm{ACC}$ & $\mathrm{ACA}$ & $\mathrm{CAA}$ & $\mathrm{ACC}$ & $\mathrm{ACA}$ & CAA & ACC & $\mathrm{ACA}$ & CAA & $\mathrm{ACC}$ & $\mathrm{ACA}$ & $\ldots$ & $\ldots T$ \\
\hline $1 d \mathrm{~b}$ & (B2) & $\ldots \ldots$ & $\ldots$ &. $\mathrm{AA}$ & $\mathrm{ACC}$ & $\mathrm{ACA}$ & -- & --- & --- & --- & --- & --- & --- & --- & --- & --- & --- & --- & --- & --- & --- & --- & --- & --- & $\ldots$ & $\ldots T$ \\
\hline ar & B7 & $\cdots$ & $\ldots$ &.-- & --- & --- & -- & --- & --- & --- & --- & --- & --- & --- & --- & --- & --- & --- & --- & --- & --- & --- & --- & --- & - & . \\
\hline pic & P3 & $\cdots \cdots$ & $\ldots$ & $\cdot--$ & --- & --- & --- & --- & --- & --- & --- & --- & --- & --- & --- & --- & --- & --- & --- & --- & --- & --- & --- & --- & & $\cdots$ \\
\hline גroc & D1 & . $\ldots$ & $\ldots$ &.-- & --- & --- & --- & --- & --- & --- & --- & --- & --- & --- & --- & --- & --- & --- & --- & --- & --- & --- & --- & --- & $\begin{array}{lll}- & \\
- & \end{array}$ & $\cdots$ \\
\hline $\mathrm{ce}$ & ( & . $\ldots$ & $\ldots$ &.-- & --- & --- & --- & --- & --- & --- & --- & --- & --- & --- & --- & --- & --- & --- & --- & --- & --- & --- & --- & --- & - & $\cdots$ \\
\hline t & & . . $\ldots$ & $\ldots$ &.-- & --- & --- & --- & --- & --- & --- & --- & --- & --- & --- & --- & --- & --- & --- & --- & --- & --- & --- & --- & --- & . & $\cdots$ \\
\hline & & 6,851 & & & & & & & & & & & & & & & & & & & & & & & raI & 16,9 \\
\hline & J237003) & CCA TAA & ATA & AAT & TTA & AAA & TTA & CAA & CAC & AAT & $\mathrm{AAC}$ & СTC & $\mathbf{C} \mathrm{CA}$ & $\mathrm{AAA}$ & TAT & AAG & $\mathrm{CAC}$ & СТA & TTT & AAG & TAT & ACG & $\mathrm{CCC}$ & $\mathrm{ACA}$ & $A T \mathbf{C} \quad T \mathbf{G} A$ & ATA TA \\
\hline & & $\ldots \quad \ldots$ & $\ldots$ &.$G$ & . & $\ldots$ & $\ldots$ & $\ldots$ & $\ldots$ & $\ldots$ & $\ldots$ & . & T. & $\ldots$ & $\ldots$ & $\ldots$ & . & $\ldots$ & . & $\ldots$ & $\cdots$ & . & $\cdots$ & $\cdots$ & .T.A. & \\
\hline ar & & $\cdots$ & $\ldots$ &. $\mathrm{G}$. & $\ldots$ & $\ldots$ & $\ldots$ & $\ldots$ & $\ldots$ & $\ldots$ & . & $\ldots$ & T. & $\ldots$ & $\ldots$ & $\ldots$ & . & $\ldots$ & $\ldots$ & $\ldots$ & $\ldots$ & $\ldots$ & . & 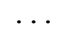 & .T.A. & \\
\hline ar & & . . c.. & $\ldots$ &.$G$. & $\ldots$ & $\ldots$ & $\ldots$ & $\ldots$ & $\ldots$ & $\ldots$ & $\ldots$ & $\ldots$ & $\ldots$ & $\cdots$ & $\cdots$ & $\cdots$ & $\ldots$ & $\cdots$ & $\cdots$ & $\cdots$ & C. . & $\cdots$ & $\cdots$ & $\cdots$ & . & . \\
\hline & & . . C.. & $\cdots$ &.$G$ & $\cdots$ & $\cdots$ & $\cdots$ & $\cdots$ & $\cdots$ & $\cdots$ & $\ldots$ & $\ldots$ & $\ldots$ & $\cdots$ & $\cdots$ & $\cdots$ & $\ldots$ & $\cdots$ & $\cdots$ & $\cdots$ & C. . & $\ldots$ & $\cdots$ & $\cdots$ & $\cdots$ & $\cdots$ \\
\hline pig & & . . C. . & $\ldots$ & . G. & $\ldots$ & $\ldots$ & $\ldots$ & $\ldots$ & $\ldots$ & $\ldots$ & $\ldots$ & $\ldots$ & $\ldots$ & $\ldots$ & $\ldots$ & $\ldots$ & $\ldots$ & $\ldots$ & $\ldots$ & $\ldots$ & C.. & $\ldots$ & $\cdots$ & $\cdots$ & $\cdot$ & $\cdots$ \\
\hline hite & & . & $\cdots$ & $\cdots$ & $\cdots$ & $\cdots$ & $\cdots$ & $\cdots$ & $\cdots$ & $\cdots$ & $\cdots$ & $\cdots$ & $\cdots$ & $\cdots$ & $\cdots$ & $\cdots$ & $\cdots$ & $\cdots$ & $\cdots$ & $\cdots$ & $\ldots$ & $\cdots$ & $\cdots$ & $\cdots$ & & $\cdots$ \\
\hline hce & 003) & CA TAA & A & AAT & TTA & A & TTA & ( & C & AAT & AAC & c & $\mathrm{C} C \mathrm{~A}$ & AAA & TAT & AAG & $\mathrm{AC}$ & СТА & TTT & AAG & $\mathrm{T}$ & ACG & $\mathrm{CC}$ & A & & $\mathrm{TA}$ \\
\hline
\end{tabular}

Fig. 2. DNA sequence alignment of part of the mitochondrial D-loop region of selected wild boar, village pig and exotic pigs (Duroc, Land race \& Large white) from Table 1. Dot (.) and dash (-) indicates, nucleotide identity and deletions respectively, according to the reference sequence (FJ237003). Bold and highlighted nucleotide positions in the reference sequence indicate the polymorphic sites of wild boar from other pigs. The region used for restriction analysis (DraI - TTTAAA) is shown with shadow. The highlighted sequences indicate the AAACCACAC repetitive sequence in Sri Lankan wild boar. Numbering is according to the reference sequence excluding deletions. 


\section{CONCLUSIONS}

Specific amplification of mtDNA D-loop region, followed by restriction analysis of amplicons with $\mathrm{DraI}$ endonuclease, provide a valuable basis for differentiating wild boar from domestic swine, offering a useful tool to reveal fraud in meat substitutions as well as in legal cases to verify wild boar meat.

\section{ACKNOWLEDGEMENT}

We thank Maheshika Kurukulasooriya for excellent support (University of Peradeniya, Sri Lanka), National Science Foundation (NSF) for financial assistance and International Atomic Energy Agency (IAEA) for supporting the visiting scholar.

\section{REFERENCES}

Alves, E., Fernández, A.I. and Fernández-Rodríguez, A. (2009). Identification of mitochondrial markers for genetic traceability of European wild boars and Iberian and Duroc pigs. Animal. 3, 1216-1223.

Arslan, A., Ilhak, I. and Calicioglu, M. (2005). Identification of meats using random amplified polymorphic DNA (RAPD) technique. J. Muscle Foods. 16, 37-45.

Arslan, A., Ilhak, O.I. and Calicioglu, M. (2006). Effect of method of cooking on identification of heat processed beef using polymerase chain reaction (PCR) technique. Meat Sci. 72, 326-330.

Ashoor, S.H., Monte, W.C. and Stiles, P.G. (1998). Liquid chromatographic identification of meats. J. Assoc. Off. Anal. Chem. 71(2), 397-403.

Chandrasiri, A.D.N. (2004). The state of animal genetic resources in Sri Lanka. Veterinary Research Institute, Peradeniya, Sri Lanka.

Dooley, J.J., Paine, K. E. and Garrett, S. D. (2004). Detection of meat species using TaqMan real-time PCR assays. Meat Sci. 68, 431-438.

Fajardo, V., González, I. and Martín, I. (2008). Real-time PCR for detection and quantification of red deer (Cervus elaphus), fallow deer (Dama dama), and roe deer (Capreolus capreolus) in meat mixtures. Meat Sci. 79, 289-298.

Fajardo, V., González, I. and López-Calleja, I. (2007). PCR identification of meats from chamois (Rupicapra rupicapra), Pyrenean ibex (Capra pyrenaica), and mouflon (Ovis ammon) targeting specific sequences from the mitochondrial D-loop region. Meat Sci. 76, 644-652.

Fajardo, V., González, I. and López-Calleja, I. (2006). PCR-RFLP authentication of meats from red deer (Cervus elaphus), fallow deer (Dama dama), and roe deer (Capreolus capreolus), cattle (Boss taurus), sheep (Ovis aries), and goat (Capra hircus). J. Agric. Food. Chem. 54, 1144-1150.

Ghivizzani, S.C., Mackay, S.L.D. and Madsen, C.S. (1993). Transcribed heteroplasmic repeated sequences in the porcine mitochondrial DNA D-loop region. J. Mol. Evol. 37, 3647. 
Hoffman, L.C. and Wiklund, E. (2006). Game and venison-meat for the modern consumer. Meat Sci. 74, 197-208.

Hwang, D.F., Jen, H.C. and Hsieh, Y.W. (2004). Applying DNA techniques to the identification of the species of dressed toasted eel products. J. Agric. Food. Chem. 52, $5972-$ 5977.

Jianlin, H. (2004). Handbook of laboratory exercises. Training programme on molecular characterization of animals. Agriculture Biotechnology Centre, University of Peradeniya, Sri Lanka, pp. 23-25.

Koh, M.C., Lim, C.H. and Chua, S.T. (1998). Random amplified polymorphic DNA (RAPD) fingerprints for identification of red meat animal species. Meat Sci. 48, 275-285.

La Neve, F., Civera, T., Mucci, N. (2008). Authentication of meat from game and domestic species by SNaPshot minisequencing analysis. Meat Sci. 80, 216-224.

Larson, G., Liu, R. and Zhao, X. (2010). Patterns of East Asian pig domestication, migration and turnover revealed by modern and ancient DNA. Proc. Nat. Acad. of Sci. USA. 107(17), 7686-7691.

Lin, C.S., Sun, Y.L. and Liu, C.Y. (1999). Complete nucleotide sequence of pig (Sus scrofa) mitochondrial genome and dating evolutionary divergence within Artiodactyla. Gene. 236(1), 107-114.

Montiel-Sosa, J.F., Ruiz-Pesini, E. and Montoya, J.. (2000). Direct and highly speciesspecific detection of pork meat and fat in meat products by PCR amplification of mitochondrial DNA. J. Agric. Food. Chem. 48, 2829-2832.

Meyer, R., Hofelein, C. and Luthy, J. (1995). Polymerase chain reaction-restriction fragment length polymorphism analysis: A simple method for species identification in food. J. Assoc. Off. Anal. Chem. 78, 1542-1551.

Naya, Y., Horiuchi, M. and Ishiguru, N. (2003). Bacteriological and genetic assessment of game meat from Japanese wild boars. Agric. Food. Chem. 51, 345-349.

Rajamahendran, R., Ravindran, V. and Goonewardena, L.A. (1986). The native pig of Sri Lanka. Animal Genetic Resources Information Bulletin (FAO),4,9-12.

Rastogi, G., Dharne, M S. and Walujkar, S. (2007). Species identification and authentication of tissue of animal origin using mitochondrial and nuclear markers. Meat Sci. 76, 666-674.

Sbisa', E., Tanzariello, F. and Reyes, A. (1997). Mammalian mitochondrial D-loop region structural analysis: identification of new conserved sequences and their functional and evolutionary implications. Gene. 31, 125-140.

Subalini E., Silva G.L.L.P. and Demetawewa C.M.B. (2010) Phenotypic Characterization and Production Performance of Village Pigs in Sri Lanka. Tropic. Agric. Res. 21, 198-208.

Wolf, C., Rentsch, J. and Hubner, P. (1999). PCR-FRLP analysis of mitochondrial DNA: A reliable method for species identification. J. Agric. Food. Chem. 47, 1350-1355. 